\title{
MINERALIZAÇÕES DE Sn DO MACIÇO GRANÍTICO SERRA BRANCA, GOIÁS: EVOLUÇÃO DO SISTEMA HIDROTERMAL E FONTE DOS FLUIDOS
}

\author{
CRISTINA V. PINTO-COELHO ${ }^{1}$ \& MÁRCIA ABRAHÃO MOURA ${ }^{2}$
}

\begin{abstract}
Resumo O maciço granítico Serra Branca (MGSB) situa-se na Província Estanífera de Goiás e pertence à suíte de granitos intraplaca paleo a mesoproterozóicos, que compreende granitos ricos em F, Sn, Rb, Y, Th, Nb, Ga e ETR. O maciço hospeda mineralização de estanho e compreende quatro fácies petrográficas distintas: a) granito rosa a cinza, heterogranular, porfirítico, médio a grosso (g1a); b) granito cinza a róseo, heterogranular médio a grosso (glb); c) granito cinza heterogranular, médio a grosso (g1c) e d) granito cinza heterogranular, médio (g1d), ocorrendo localizadamente na porção oriental do maciço. Ocorrem, ainda, greisens apicais e filões micáceos. Importantes fenômenos pós-magmáticos são identificados, representados inicialmente por albitização, seguida por greisenização (a mais desenvolvida) e, finalmente, microclinização. Estudos de inclusões fluidas em feldspato alcalino das fácies graníticas (g1a) e (g1c), em quartzo, topázio e fluorita do granito (g1d), de greisen e de veios de quartzo + fluorita e quartzo + topázio revelaram a presença de 2 tipos de inclusões fluidas: tipo 1, que compreende inclusões fluidas modeladas pelo sistema $\mathrm{H}_{2} \mathrm{O}-\mathrm{NaCl}-\mathrm{CO}_{2}\left( \pm \mathrm{CH}_{4}\right)$, interpretadas como primárias; e tipo 2, constituído por inclusões fluidas bifásicas $\mathrm{H}_{2} \mathrm{O}-\mathrm{NaCl} \pm$ $\left(\mathrm{KCl}-\mathrm{MgCl}_{2}-\mathrm{FeCl}_{2}\right)$, com características de inclusões primárias nas rochas hidrotermais e secundárias em quartzo da fácies $(\mathrm{g} 1 \mathrm{a})$. Os baixos valores de $\mathrm{T}_{\mathrm{H}}\left(\sim 240^{\circ} \mathrm{C}\right)$ e de salinidade $(<2 \%$ em peso de $\mathrm{NaCl}$ equiv.) das inclusões fluidas dos núcleos dos feldspatos alcalinos sugerem que essas porções não contêm mais o fluido magmático aprisionado, mas fluidos resultantes de resfriamento progressivo ou de alteração hidrotermal. As características petrológicas dos granitos do MGSB e os dados de inclusões fluidas são consistentes com fonte predominantemente magmática para os fluidos ricos em $\mathrm{CO}_{2}\left( \pm \mathrm{CH}_{4}\right)$. Os dados petrográficos e microtermométricos sugerem que os fluidos aquosos são posteriores aos aquo-carbônicos. Propõe-se um modelo de evolução com liberação residual de um fluido inicialmente magmático e mistura com fluido externo de mais baixa temperatura. Após a alteração hidrotermal e mineralização houve aprisionamento de fluidos tardios em fraturas de minerais hidrotermais, possivelmente resultante de deformação ligada ao Ciclo orogenético Brasiliano, onde as perturbações térmicas e deformacionais encontram-se registradas nas rochas graníticas e greisens do maciço.
\end{abstract}

Palavras-chave: granito, Província Estanífera de Goiás, estanho, alteração hidrotermal, inclusões fluidas

\begin{abstract}
TIN MINERALIZATION IN THE SERRA BRANCA GRANITIC MASSIF, GOIÁS, BRAZIL: EVOLUTION MODEL OF THE HYDROTHERMAL SYSTEM AND THE SOURCE OF THE FLUIDS. The Serra Branca granitic massif occurs in the Goiás tin province and is part of the Paleo- to Mesoproterozoic within-plate granites suite, which is rich in F, Sn, Rb, Y, Th, Nb, $\mathrm{Ga}$ and REE. The Serra Branca granitic massif hosts tin mineralization and comprises: a) pink to gray, porphyritic, medium- to coarse-grained granite (g1a); b) pink to gray, heterogranular, medium- to coarse-grained granite (g1b); c) gray, heterogranular, medium- to coarse-grained granite (g1c); and d) gray, heterogranular, medium-grained granite (g1d), which is restricted to the eastern part of the massif. Greisens and mica veins also occur in the massif. Important post-magmatic processes have been identified: albitization, greisenization (the most prominent) and microclinization. A fluid inclusion study in K-feldspar from the (g1a) and $(\mathrm{g} 1 \mathrm{c})$ granites and in quartz, topaz and fluorite from the (g1d) granite, greisen and quartz + fluorite and quartz + topaz veins revealed the presence of two fluid inclusions types: i) type 1, interpreted as primary and modeled by the $\mathrm{H}_{2} \mathrm{O}-\mathrm{NaCl}_{-}-\mathrm{CO}_{2}\left( \pm \mathrm{CH}_{4}\right)$ system; and ii) type 2, composed of $\mathrm{H}_{2} \mathrm{O}-\mathrm{NaCl} \pm\left(\mathrm{KCl}-\mathrm{MgCl}_{2}-\mathrm{FeCl}_{2}\right)$ two-phase fluid inclusions, with petrographic characteristics of primary fluid inclusions in the hydrothermal rocks and of secondary ones in quartz from the (g1a) granite. The low $\mathrm{T}_{\mathrm{H}}\left(\sim 240^{\circ} \mathrm{C}\right)$ and salinity $(<2$ wt. \% NaCl equiv.) values of fluid inclusions entrapped in $\mathrm{K}$-feldspar from the granites suggest that this mineral doesn't contain the original magmatic fluid, but fluids derived either from progressive cooling or from late hydrothermal alteration. The petrologic characteristics of the Serra Branca massif together with the fluid inclusions data are consistent with predominant magmatic source for the fluids rich in $\mathrm{CO}_{2}\left( \pm \mathrm{CH}_{4}\right)$. The petrographic and microthermometric data suggest that the aqueous fluids were entrapped later. It is proposed an evolution model in which an initially magmatic fluid has been released and mixed with external lower-temperature fluid. After the hydrothermal alteration and mineralization, there was entrapment of late fluids in fractures of the hydrothermal minerals, probably due to the deformation associated with the Brasilano orogenic event.
\end{abstract}

Keywords: granite, Goiás tin province, tin, hydrothermal alteration, fluid inclusions, Brazil

INTRODUÇÃO Nos estados de Goiás e Tocantins, depósitos de estanho relacionados a granitos produziram aproximadamente $15 \mathrm{Kt}$ de concentrado de estanho desde 1960. Os depósitos mais importantes associam-se a granitos intraplaca paleo a mesoproterozóicos $(1,78$ a $1,50 \mathrm{Ga})$ pertencentes à Província Estanífera de Goiás (Marini \& Botelho 1986), ricos em F, $\mathrm{Sn}, \mathrm{Rb}, \mathrm{Y}, \mathrm{Th}, \mathrm{Nb}$, Ga e ETR (Botelho \& Moura 1998, Lenharo et al. 2002).

A porção norte da Província Estanífera de Goiás, a mais importante em termos de mineralização de estanho, divide-se em duas subprovíncias: Rio Tocantins, a oeste, e Rio Paranã, a leste (Marini \& Botelho 1986). O Maciço Granítico da Serra Branca (MGSB) situa-se na subprovíncia Rio Tocantins e é intrusivo no embasamento do Cinturão de dobramentos Brasília. Localiza-se no extremo norte do Estado de Goiás, a aproximadamente 600 $\mathrm{Km}$ de Brasília e a $22 \mathrm{Km}$ a SE do distrito de Minaçu, e limitase pelos paralelos $13^{\circ} 33^{\prime} 45^{\prime \prime}$ e $13^{\circ} 38^{\prime} 50^{\prime \prime}$ de latitude S e pelos meridianos $48^{\circ} 07^{\prime} 13^{\prime \prime}$ e $48^{\circ} 05^{\prime} 34^{\prime \prime}$ de longitude W. A geologia e metalogenia do MGSB foram estudadas em detalhe por PintoCoelho (1996).

1 - Universidade Federal do Paraná - UFPR - Departamento de Geologia - DEGEOL. Centro Politécnico, s/nº Jardim das Américas. Caixa Postal 19.001 - CEP 81.531-990. Curitiba - PR - Brasil. e-mail: cristinavpc@ufpr.br

2 - Universidade de Brasília - UnB - Instituto de Geociências. Campus Universitário Darcy Ribeiro - Asa Norte. CEP 70910-900. Brasília - DF - Brasil. e-mail: mamoura@unb.br 
Neste trabalho, são apresentados e discutidos resultados do estudo de inclusões fluidas em minerais (feldspato potássico, fluorita, topázio e quartzo) de granitos e de rochas hidrotermais do Maciço granítico Serra Branca com o objetivo de estimar as características físico-químicas dos fluidos formadores dessas rochas e do depósito de estanho. São apresentados pela primeira vez na literatura dados sobre os fluidos relacionados à mineralização de estanho da subprovíncia Rio Tocantins, o que possibilita a comparação com as condições de formação de depósitos semelhantes da Província Estanífera de Goiás e de outras áreas.

\section{O MACIÇO GRANÍTICO DA SERRA BRANCA}

MGSB forma uma estrutura elíptica, com eixo maior direcionado N15W, dominada por quartzitos sub-horizontais atribuídos ao Grupo Araí, de idade Paleoproterozóica (Figura 1). O maciço encontra-se fortemente estruturado, adquirindo, na parte E, uma xistosidade plana tangencial sub-horizontal, relacionada tectonicamente ao evento orogenético Brasiliano.

Os quartzitos Araí formam uma coroa quase contínua ao longo de todo o corpo granítico, onde as altitudes mais elevadas encontram-se nas bordas leste e sul. Apesar dessa morfologia particular, aparentemente invertida, a estruturação geral do conjunto é aquela de um domo perfeitamente circunscrito.

O exame macroscópico das rochas amostradas revela a existência de variações petrográficas importantes no MGSB, levando à definição, baseada em diferenças mineralógicas e texturais, de quatro fácies petrográficas distintas (Figura 1): a) granito rosa a cinza (g1a), heterogranular, porfiróide médio a grosso; b) granito cinza a róseo $(\mathrm{g} 1 \mathrm{~b})$, heterogranular médio a grosso; c) granito cinza (glc) heterogranular, médio a grosso e d) granito cinza (g1d) heterogranular, médio, ocorrendo localizadamente na porção oriental do maciço. Ocorrem, ainda, greisens apicais e filões micáceos. As fácies (g1b) e (g1d) não foram individualizadas no mapa geológico da Figura 1 por não possuírem dimensões mapeáveis na escala adotada.

Os dados modais distribuem-se, preferencialmente, no domínio 3 do diagrama QAPF (Le Maître et al. 1989), correspondendo aos granitos s.s. $(3 \mathrm{a}=$ sienogranitos; $3 \mathrm{~b}=$ monzogranitos $)$ (Pinto-Coelho 1996).

A fácies rosa a cinza (gla) encontra-se fortemente deformada, com desenvolvimento de foliação inclinada para W, aflorando na porção ocidental do maciço. A mineralogia essencial está representada por quartzo, biotita, feldspato potássico e albita. Minerais acessórios estão representados por zircão, allanita, apatita, monazita e raros opacos (ilmenita). O feldspato potássico (microclínio) apresenta-se em três gerações de cristalização distintas: (i) fenocristais com tendência subautomórfica, com blastese nas bordas e presença acentuada de inclusões fluidas; (ii) cristais subautomórficos a xenomórficos, comumente intersticiais, e com acentuado aspecto turvo, e (iii) uma terceira geração representada por indivíduos límpidos, desprovidos de quaisquer inclusões e restritos à matriz da rocha. Dados obtidos em microssonda eletrônica revelam composições $\mathrm{Or}_{93-97} \mathrm{Ab}_{7-3}$ para os feldspatos alcalinos destes granitos (Pinto-Coelho 1996). O quartzo mostra-se, sobretudo, em agregados policristalinos, bem circunscritos e fortemente recristalizados. O plagioclásio apresenta, igualmente ao feldspato potássico, três gerações de cristalização: cristais subautomórficos a xenomórficos, pouco alongados, com maclas polissintéticas simples pouco deformadas, por vezes em fenocristais; contém, freqüentemente, alteração para muscovita e minerais argilosos. Não foi observado qualquer zoneamento químico entre as bordas e os núcleos destes minerais, cujas composições variam sistematicamente entre $\mathrm{Ab}_{93}$ e $\mathrm{Ab}_{98}$ (Pinto-Coelho op. cit.). A segunda geração de plagioclásio está representada por indivíduos menores, igualmente subautomórficos a xenomórficos, geralmente límpidos e com poucas inclusões sólidas; sua composição química assemelhase à dos plagioclásios de primeira geração. Observa-se, por vezes, textura do tipo mirmequita. O terceiro tipo de plagioclásio é constituído pela geração de albita sob forma de exsoluções em feldspato potássico de primeira geração. A biotita ocorre preferencialmente em agregados policristalinos, comumente associada à muscovita; mais raramente é observada como inclusões em quartzo e feldspato alcalino.

Processo pós-magmático de albitização encontra-se marcado nesta fácies pela presença de albita do tipo chess board nas bordas de fraturas que seccionam os fenocristais de feldspato alcalino pertítico.

A fácies granítica cinza a rósea $(\mathrm{g} 1 \mathrm{~b})$ exibe características petrográficas semelhantes às da fácies (g1a), exceto no que se refere ao aumento da deformação e maiores proporções modais de quartzo, muscovita, fluorita, microclínio tardio e fases minerais acessórias radioativas e à terras raras, denotando, assim, maior desenvolvimento de processos de alteração pós-magmáticos (Pinto-Coelho et al. 1999). Encontram-se, nesta fácies, cristais reliquiares de plagioclásio $\mathrm{An}_{20-23}$ e de granada almandina, interpretada, com base na sua composição química, como resultante de origem crustal profunda (Pinto-Coelho 1996).

A fácies cinza (g1c) é a mais diferenciada do MGSB. Aflora na porção oriental do maciço e sua mineralogia resume-se a quartzo, albita, microclínio pertítico e muscovita secundária, com as proporções modais desta última sendo nitidamente superiores às das demais fácies. Manchas de albita, grosseiramente coalescentes, desenvolvem-se sobre o microclínio desta fácies, correspondendo, possivelmente, a vestígios do processo de albitização. $\mathrm{O}$ feldspato alcalino de primeira geração, em fenocristais, mostra manchas de exsolução de albita com mesma orientação óptica e inúmeras inclusões fluidas, que poderiam, igualmente, corresponder à albitização.

Na porção oriental do maciço encontra-se a fácies granítica cinza (g1d), com características petrográficas semelhantes ao tipo anteriormente descrito, exceto no que se refere à presença de topázio que, nesta fácies, ocorre em proporções modais médias em torno de 4\%. Os minerais acessórios mais freqüentes nesta fácies são zircão, apatita, allanita, monazita e opacos (ilmenita). Contato tectônico por falha é observado entre as fácies (g1a) e (g1c); os contatos entre as demais fácies não foram observados no campo.

Importantes variações observadas na composição modal dos granitos do MGSB resultaram da atuação de fenômenos pósmagmáticos: albitização, greisenização (a mais desenvolvida) e microclinização (Pinto-Coelho \& Charoy 2001). A greisenização oblitera inteiramente a textura da rocha original e é responsável pela formação de greisens maciços observados na porção oriental do maciço. A composição mineralógica dos greisens é dominada pela associação quartzo + fengita não litinífera. Topázio, fluorita, cassiterita, berilo, monazita, scheelita, grafita, esfalerita, zoisita, zircão, apatita, fenacita, ilmenita, arsenopirita e calcopirita são acessórios freqüentes. A cassiterita encontra-se disseminada ou sob a forma de agregados com coloração castanha. São observadas várias gerações de quartzo e de mica, evidenciando assim a importância da recristalização que oblitera total ou parcialmente a textura da rocha original. Apesar da importante estruturação macroscópica, o quartzo, seja intersticial, seja em agregados policristalinos, apresenta-se moderadamente deformado, evidenciando a amplitude do fenômeno de recristalização. A fengita ocorre em lamelas deformadas, definindo xistosidade, sob forma de finas palhetas na matriz dos greisens ou, ainda, como inclusões na mineralogia acessória.

Feldspatos da rocha original são raramente preservados sob a forma de relictos albíticos, comumente inclusos em quartzo, e com composição idêntica à do plagioclásio da fácies (g1a) 


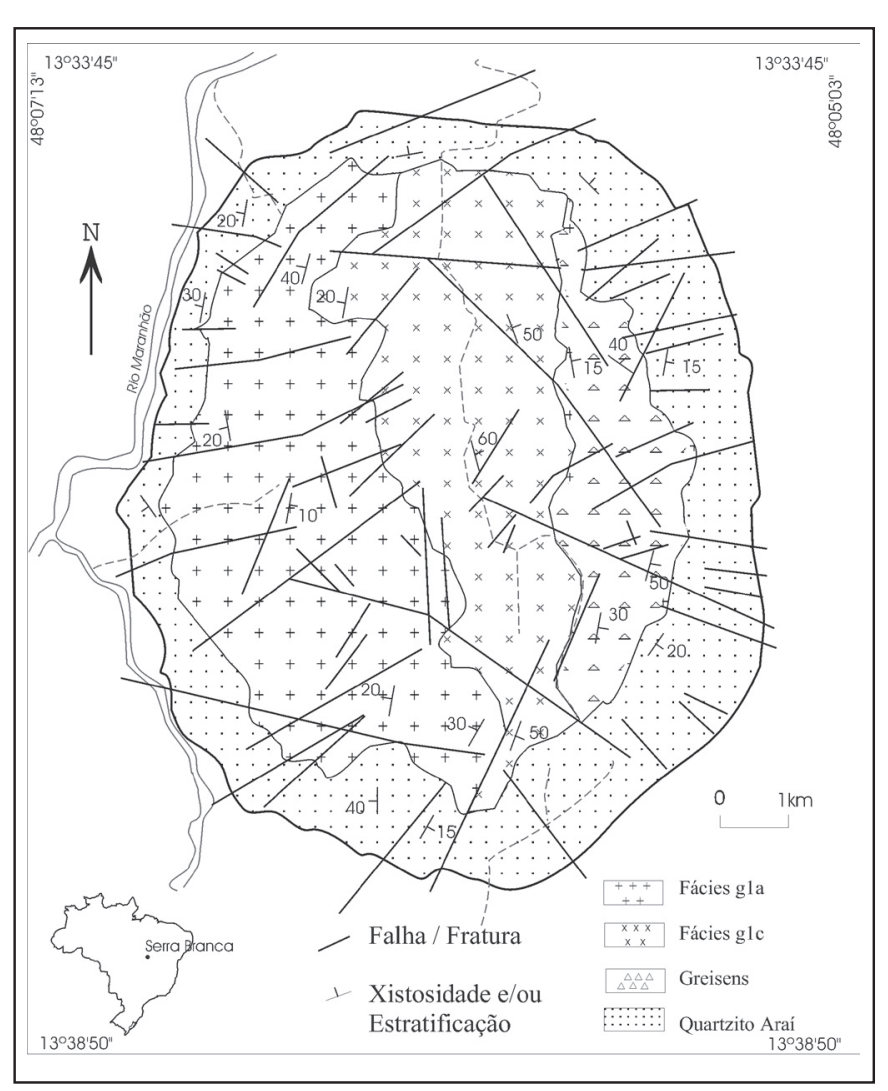

Figura 1 - Mapa geológico simplificado do Maciço granítico Serra Branca e encaixantes (modificado de Andrade, 1978). As fácies glb e gld não foram individualizadas por não possuírem dimensões mapeáveis na escala adotada.

$\left(\mathrm{Ab}_{97-99} \mathrm{An}_{1-3}\right)$. O feldspato potássico neoformado (microclínio não pertítico, com geminação em grade bem desenvolvida, desprovido de qualquer exsolução albítica, inclusão mineral ou fluida e composição idêntica à dos feldspatos observados nas fácies graníticas, com composição $\mathrm{Or}_{94-96} \mathrm{Ab}_{4-6}$ ) é visivelmente posterior à deformação geral, cimentando a cassiterita. Assim, o fenômeno de microclinização das fácies graníticas é claramente posterior à greisenização (Pinto-Coelho \& Charoy 2001). Nas fácies graníticas, o feldspato neoformado desenvolve-se, preferencialmente, nas bordas do microclínio precoce, mas ocorre, ainda, associado à matriz dos granitos. Nos greisens, as fases feldspáticas iniciais foram substituídas pelo microclínio tardio.

Filões micáceos orientados NS a N15-30W associam-se, preferencialmente, à fácies (g1a) e aos greisens. Compõem-se de $95 \%$ de micas com granulação fina a muita fina e coloração esverdeada característica; secundariamente ocorrem quartzo, topázio, zircão, apatita, opacos (predominantemente ilmenita e calcopirita) e, mais raramente, epidoto e fenacita. Estes filões, assim como os greisens, são afetados por foliação sub-horizontal ou levemente inclinada para $\mathrm{E}$.

A superimposição do evento orogenético Brasiliano marcase, no MGSB, pela intensa deformação a que as fácies graníticas e greisens foram submetidas e pode ser confirmada por dados geocronológicos K/Ar obtidos em muscovita. Os resultados fornecem idades que variam entre 504 e 540 M.a, contrariamente às idades $\mathrm{U} / \mathrm{Pb}$ obtidas em monazitas, que situam-se entre $1.14 \mathrm{e}$ 1.35 G.a (Pinto-Coelho 1996). Assim, as perturbações térmicas e deformacionais associadas a esse evento foram responsáveis pela abertura do sistema das micas e denotam a importância de uma fase fluida atuante após a alteração hidrotermal e mineralização.
ESTUDO DE INCLUSÕES FLUIDAS O estudo de inclusões fluidas foi realizado em (i) cristais de feldspato potássico precoce (microclínio) das fácies graníticas do MGSB, (ii) em fluorita da fácies (g1d) e dos filões micáceos; (iii) em topázio do greisen e topázio de um veio quartzo + topázio; e (iv) em quartzo do granito (g1d), quartzo do greisen e de veio de quartzo + fluorita. Os filões micáceos associados ao MGSB foram descritos como greisens fissurais por Andrade (1978); Botelho (1992) descreveu-os como pseudo-greisens miloníticos.

Nas fácies (g1a) e (g1c) do MGSB, o feldspato alcalino da primeira geração de cristalização (microclínio) caracteriza-se pela presença de inúmeras inclusões fluidas, constituindo-se em um forte critério de reconhecimento e distinção em luz natural entre os dois tipos de feldspato (alcalino e plagioclásio). Tais inclusões possuem tamanho médio em torno de $5 \mu \mathrm{m}$ (Figura 2a), concentrando-se, preferencialmente no núcleo dos cristais. Estão ausentes, ou obliteradas, nas bordas (Figuras $2 \mathrm{~b}$ e c), quando a geminação albita-periclina é bem desenvolvida (Figura 2d), ou nas bordas de manchas de exsolução de albita (Figura 2e). Essa particularidade dos feldspatos alcalinos contrasta fortemente com o aspecto apresentado pelo plagioclásio, que mostra grande densidade de inclusões minerais, essencialmente fengita e fluorita.

$\mathrm{Na}$ fluorita da fácies (g1d) e do filão micáceo, a escassez de inclusões fluidas é notável, o que dificultou a análise microtermométrica. Cristais de topázio dos greisens e de um veio quartzo + topázio são ricos em inclusões fluidas, ao contrário do observado no granito (g1d), onde as inclusões fluidas presentes não puderam ser analisadas em função da raridade e das dimensões extremamente reduzidas.

Três amostras foram selecionadas para o estudo microtermométrico de inclusões fluidas em quartzo: a) fácies (g1d); b) greisen e c) veio com quartzo + fluorita. Na fácies (g1d) a deformação e a recristalização dificultaram o estudo das inclusões fluidas em quartzo, com o fenômeno de estrangulamento sendo freqüentemente observado (Figura 3a).

As medidas microtermométricas das inclusões fluidas foram realizadas no Centre de Recherches Pétrographiques et Géochimiques - C.R.P.G. - França, em platina U.S.G.S., de fluxo gasoso, em baixa temperatura $\left(\mathrm{de}-180^{\circ} \mathrm{C} \mathrm{a}+30^{\circ} \mathrm{C}\right)$ e alta temperatura (de $+30^{\circ} \mathrm{C} \mathrm{a}+600^{\circ} \mathrm{C}$ ), acoplada a microscópio Leitz, munido com objetiva UNT $32 \mathrm{~mm}$.

Com base nas características petrográficas em temperatura ambiente e nos dados de microtermometria, as inclusões fluidas estudadas foram classificadas em dois tipos. O tipo 1 compreende inclusões fluidas aquo-carbônicas, interpretadas como primárias, que ocorrem em todas as amostras estudadas. O tipo 2 compreende inclusões fluidas bifásicas aquosas, com características petrográficas de inclusões primárias nas rochas hidrotermais e de inclusões fluidas secundárias (preenchendo planos de fratura) em quartzo da fácies (g1d).

\section{Características petrográficas e microtermométricas}

TIPO 1- INCLUSÕES AQUO-CARBÔNICAS As inclusões fluidas do tipo 1 ocorrem em todas as amostras estudadas e possuem características petrográficas de inclusões fluidas primárias. Caracterizam-se por serem predominantemente aquo-carbônicas em temperatura ambiente. Localmente, contêm sólido cúbico e sólidos birrefringentes. Tendo em vista não haver populações de inclusões fluidas (FIA) contendo sólido cúbico, segundo os critérios de Goldstein \& Reynolds (1994), a possibilidade desse grupo de inclusões fluidas ser resultado de processo de necking down não pode ser descartada, motivo pelo qual ele foi incluído juntamente com as inclusões fluidas classificadas como do tipo 1. Os sólidos birrefringentes foram interpretados como capturados, com base em critérios propostos por Shepherd et al. (1985).

As inclusões fluidas inseridas no tipo 1 possuem formas va- 
riadas e grau de preenchimento $(\mathrm{Vg})$ predominantemente entre 20 e $30 \%$. A temperatura de fusão da fase carbônica $\left(\mathrm{TfCO}_{2}\right)$ varia de $-58,2^{\circ}$ a $-56,6^{\circ} \mathrm{C}$, com moda entre $-56,8^{\circ}$ e $-56,6^{\circ} \mathrm{C}$ (Tabela 1; Figura 4a). A temperatura de fusão do clatrato não pôde ser medida, possivelmente devido ao baixo conteúdo de sal na maioria das inclusões fluidas estudadas. A temperatura de fusão do gelo situa-se entre $-12^{\circ}$ e $-0,1^{\circ} \mathrm{C}$ (Tabela 1 ), com maior concentração de dados próximo a $-0,1^{\circ} \mathrm{C}$. A salinidade, estimada com base na temperatura de fusão do gelo, situa-se entre $0,7 \%$ e $16 \%$ em peso de $\mathrm{NaCl}$ equiv., considerando o sistema como $\mathrm{H}_{2} \mathrm{O}-\mathrm{NaCl}$ (Sheperd et al. 1985). A homogeneização da fase carbônica dá-se para o líquido, entre $24^{\circ}$ e $30^{\circ} \mathrm{C}$, o que implica densidades entre 0,65 e $0,75 \mathrm{~g} / \mathrm{cm}^{3}$. As inclusões fluidas crepitaram com frequiência durante as medidas em elevadas temperaturas. A homogeneização total, quando observada, ocorre para a fase líquida entre $190^{\circ}$ e $335^{\circ} \mathrm{C}$, predominantemente entre $240^{\circ}$ e $280^{\circ} \mathrm{C}$. (Tabela 1; Figura 4b)

As inclusões fluidas do tipo 1 em feldspato das fácies (g1a) e (g1c) têm morfologia bastante regular. São arredondadas a tabulares, com alongamento estatístico paralelo a [001] do cristal hospedeiro (Figura 2a) e aspecto globalmente homogêneo. Algumas inclusões contêm uma fase sólida birrefringente, interpretada com tendo sido aprisionada durante a formação da cavidade. $\mathrm{O}$ volume da fase volátil em relação ao volume global da inclusão à $\mathrm{T}>\mathrm{Th} \mathrm{CO}_{2}$ é de aproximadamente $20 \%$. As medidas termométricas confirmaram a homogeneidade do conteúdo dessas inclusões em feldspato alcalino. As temperaturas de fusão do $\mathrm{CO}_{2}$ situam-se entre $-58,2^{\circ}$ e $-56,7^{\circ} \mathrm{C}$ (Tabela 1 ; Figura
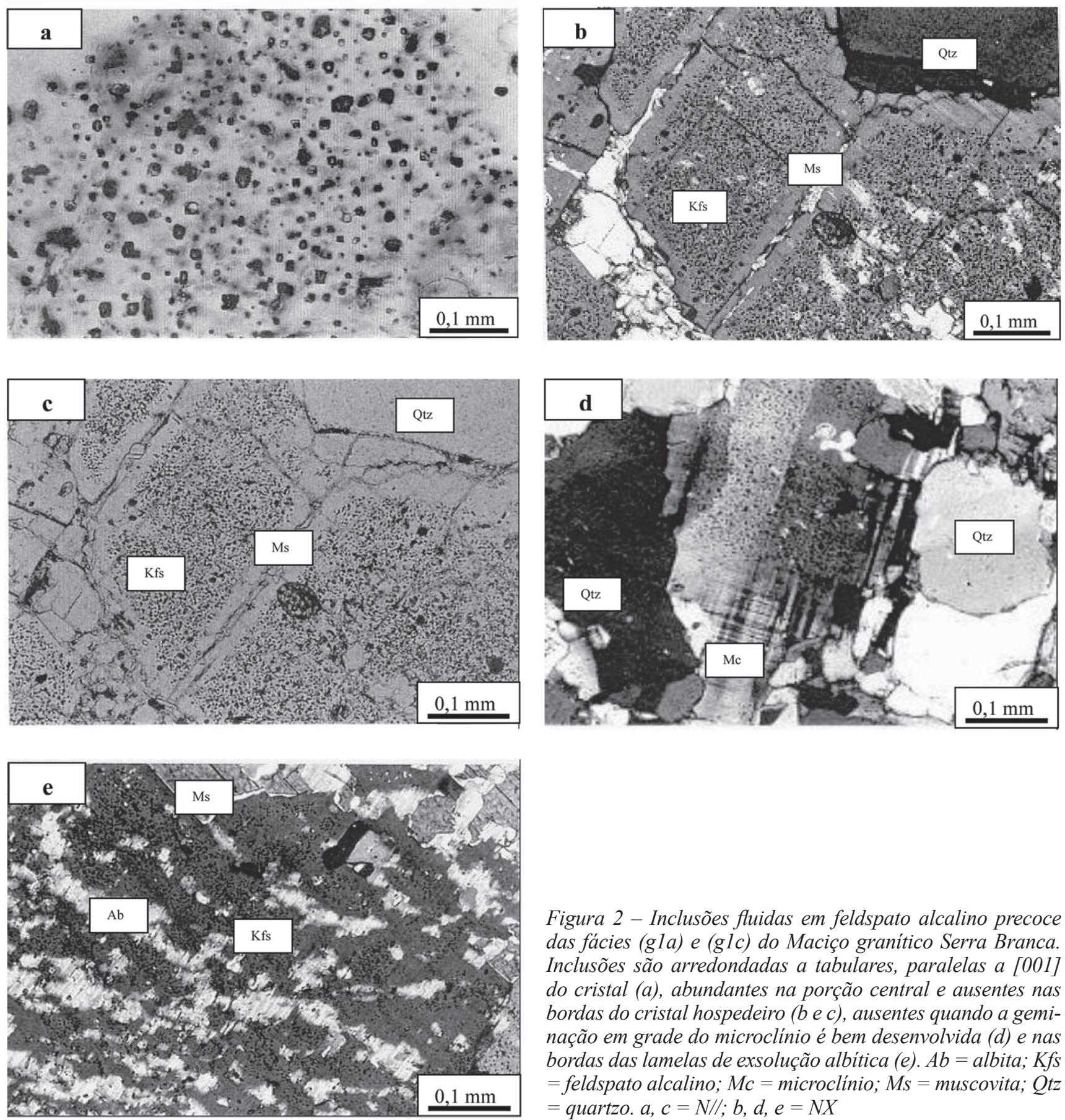

Figura 2 - Inclusões fluidas em feldspato alcalino precoce das fácies (gla) e (glc) do Maciço granítico Serra Branca. Inclusões são arredondadas a tabulares, paralelas a [001] do cristal (a), abundantes na porção central e ausentes nas bordas do cristal hospedeiro ( $b$ e c), ausentes quando a geminação em grade do microclínio é bem desenvolvida (d) e nas bordas das lamelas de exsolução albitica (e). Ab = albita; $K f S$ = feldspato alcalino; $M c=$ microclínio; $M s=$ muscovita; $Q t z$ $=$ quartzo. $a, c=N / / ; b, d, e=N X$ 
4a), o que sugere a presença de outros gases além de $\mathrm{CO}_{2}$ nas inclusões estudadas, confirmada por espectroscopia Raman, que demonstrou haver entre 3 e 5 mole $\%$ de $\mathrm{CH}_{4}$ (Figura 5). A fusão do gelo, dificilmente observável, situa-se entre $-0,9^{\circ} \mathrm{e}-0,1^{\circ} \mathrm{C}$. A salinidade da fase líquida, estimada com base na temperatura de fusão do gelo, situa-se entre 0,7 e $1,6 \%$ em peso de $\mathrm{NaCl}$ equiv. (Tabela 1). A homogeneização da parte volátil ocorre para a fase líquida, entre 26 e $29^{\circ} \mathrm{C}$, o que resulta em densidade estimada entre 0,7 e $0,75 \mathrm{~g} / \mathrm{cm}^{3}$ (Shepherd et al. 1985). A temperatura de homogeneização total foi raramente observada em função do fenômeno de crepitação. Quando observada, a homogeneização total ocorreu para fase líquida em temperatura próxima de $240^{\circ} \mathrm{C}$.

Nas inclusões aquo-carbônicas em quartzo da fácies (g1d), raras, o $\mathrm{CO}_{2}$ sólido funde entre $-56,9^{\circ}$ e $-56,6^{\circ} \mathrm{C}$. (Tabela 1 ; Figura 4a). A fusão do gelo ocorre entre $-10^{\circ}$ e $-4^{\circ} \mathrm{C}$ (Tabela 1), implicando salinidade entre 6,4 e $13,9 \%$ em peso de $\mathrm{NaCl}$ equiv.. Essas inclusões crepitam facilmente durante as medidas em alta temperatura e os únicos valores obtidos para $T_{H}$, entre $306^{\circ}$ e $350^{\circ} \mathrm{C}$, são mostrados na Figura $4 \mathrm{~b}$.

As inclusões fluidas do tipo 1 em fluorita da fácies (g1d), interpretadas como primárias, contêm freqüentemente sólidos birrefringentes. Suas dimensões médias são em torno de $8 \mu \mathrm{m}$ e o grau de preenchimento Vg é inferior a 30\% (Figura 3b). As temperaturas de fusão do $\mathrm{CO}_{2}$ concentram-se entre $-57^{\circ} \mathrm{e}$ $-56,6^{\circ} \mathrm{C}$ (Tabela 1$)$, o que sugere a presença de outra fase volátil adicionada. Entretanto, a forte fluorescência impediu a realização de espectroscopia Raman nessas inclusões. A temperatura de homogeneização do $\mathrm{CO}_{2}$, em fase líquida, situa-se entre 26 e $29^{\circ} \mathrm{C}$. A fusão do gelo, dificilmente observável, situa-se entre $-2,2^{\circ} \mathrm{C}$ e $-0,5^{\circ}$, com salinidades calculadas entre 0,8 e $3,7 \%$ em peso de $\mathrm{NaCl}$ equiv.. A temperatura de homogeneização total, em fase líquida, situa-se entre $245^{\circ}$ e $273^{\circ} \mathrm{C}$ (Tabela 1 ).

As inclusões aquo-carbônicas identificadas em topázio de veio de quartzo + topázio são comumente alongadas e arredondadas, apesar de também ocorrerem inclusões irregulares (Figuras 3c e d). Ocorrem sólidos birrefringentes, interpretados como capturados, e mais raramente sólidos cúbicos, possivelmente halita (Figura 3e). Quando observada, a temperatura do eutético (Te) situa-se entre $-33^{\circ} \mathrm{e}-24^{\circ} \mathrm{C}$ e o gelo funde-se entre $-12^{\circ} \mathrm{e}$ $-2^{\circ} \mathrm{C}$, implicando salinidade estimada de 3,4 a $15,9 \%$ em peso de $\mathrm{NaCl}$ equiv. (Tabela 1 ). A temperatura de fusão do $\mathrm{CO}_{2}$ situase entre $-57,6^{\circ}$ e $-56,6^{\circ} \mathrm{C}$ e a homogeneização da fase carbônica ocorre entre $25^{\circ}$ e $30^{\circ} \mathrm{C}$, para a fase líquida. A homogeneização total ocorre predominantemente entre $240^{\circ}$ e $280^{\circ} \mathrm{C}$ (Tabela 1 ).

As inclusões fluidas aquo-carbônicas do quartzo do veio de quartzo + fluorita possuem tamanho variável e são tanto irregulares, subarredondadas alongadas, ou em forma de cristal negativo. Algumas populações são constituídas por inclusões fluidas com tamanho superior a $10 \mu \mathrm{m}$ e volume variável da fase vapor. As temperaturas de fusão do $\mathrm{CO}_{2}$ situam-se entre $-57,8^{\circ}$ e $-56,6^{\circ} \mathrm{C}$ (Tabela 1 ; Figura $4 \mathrm{~b}$ ). A homogeneização ocorre entre $27^{\circ}$ e $30,9^{\circ} \mathrm{C}$, em fase líquida, indicando densidade da fase volátil entre 0,6 e $0,65 \mathrm{~g} / \mathrm{cm}^{3}$. A temperatura de fusão do gelo varia de $-6,9^{\circ} \mathrm{a}-3^{\circ} \mathrm{C}$, com salinidades compreendidas entre 4,9 e $10,3 \%$ em peso de $\mathrm{NaCl}$ equiv.. A homogeneização total, em fase líquida, varia de $250^{\circ}$ a $270^{\circ} \mathrm{C}$ (Tabela 1; Figura $4 \mathrm{~b}$ ).

As inclusões fluidas do tipo 1 são raras no topázio dos greisens. Apresentam $\mathrm{TfCO}_{2}$ em torno de $-57,1^{\circ} \mathrm{C}$ (Tabela 1), indicando presença de outros componentes voláteis dissolvidos. A fusão do gelo faz-se entre $-5,5^{\circ} \mathrm{e}-3^{\circ} \mathrm{C}$, o que implica salinidade entre 4,9 e $8,5 \%$ em peso de $\mathrm{NaCl}$ equiv. (Tabela 1). A homogeneização total situa-se entre $258^{\circ}$ e $270^{\circ} \mathrm{C}$ (Tabela 1; Figura 4b).

Contrariamente às inclusões fluidas observadas em quartzo da fácies (g1d), aquelas encontradas nos greisens, com dimensão média de $7 \mu \mathrm{m}$, são preferencialmente aquo-carbônicas e co- mumente contêm sólidos birrefringentes. A fusão do $\mathrm{CO}_{2}$ sólido ocorre entre $-56,6^{\circ}$ e $-57,5^{\circ} \mathrm{C}$ (Tabela 1 ), indicando presença de outra fase volátil. A porção aquosa possui Te entre $-30^{\circ} \mathrm{e}-23^{\circ} \mathrm{C}$. A Tfg varia de $-10^{\circ} \mathrm{e}-2^{\circ} \mathrm{C}$ (Tabela 1), com salinidade entre 3,4 e $14 \%$ em peso de $\mathrm{NaCl}$ equiv.. A homogeneização total ocorre entre $255^{\circ}$ e $270^{\circ} \mathrm{C}$ (Figura $4 \mathrm{~b}$; Tabela 1), com crepitação freqüente.

TIPO 2-INCLUSÕES AQUOSAS As inclusões fluidas do tipo 2 possuem características de inclusões primárias em fluorita do filão micáceo, em topázio de greisen e do veio, e em quartzo dos greisens. Nos cristais de quartzo da fácies granítica (g1d), poucas inclusões fluidas primárias estão preservadas devido ao freqüente estrangulamento a que foram submetidas (Fig. 3a). As inclusões fluidas aquosas estão preferencialmente dispostas ao longo de planos de fraturas cicatrizadas. Essas inclusões têm Te média de $-21^{\circ} \mathrm{C}$ e fusão do gelo entre $-16^{\circ} \mathrm{e}-2^{\circ} \mathrm{C}$ (Figura $4 \mathrm{c}$ ), com salinidades calculadas entre 3,4 e $19,4 \%$ em peso de $\mathrm{NaCl}$ equiv.. A temperatura de homogeneização, em fase líquida, situa-se entre $218^{\circ}$ e $258^{\circ} \mathrm{C}$ (Figura $4 d$ ).

$\mathrm{Na}$ fácies (g1d) e no veio de quartzo + fluorita, ocorrem preferencialmente ao longo de trilhas, sendo interpretadas como secundárias. Fenômenos de estrangulamento são comumente observados nas inclusões do tipo 2. Quando observada, a temperatura do eutético varia predominantemente de $-35^{\circ} \mathrm{a}-25^{\circ} \mathrm{C}$ (Tabela 1), o que permitiu modelar as inclusões fluidas pelo sistema $\mathrm{H}_{2} \mathrm{O}-\mathrm{NaCl}\left( \pm \mathrm{KCl}-\mathrm{MgCl}_{2}-\mathrm{FeCl}_{2}\right)$. A temperatura de fusão do gelo varia de $-17^{\circ}$ a $-0,8^{\circ} \mathrm{C}$ (Tabela 1; Figura 4c), resultando em salinidade entre 1,4 e $20,2 \%$ em peso de $\mathrm{NaCl}$ equiv.. A homogeneização total ocorre para a fase líquida, entre $180 \mathrm{e}$ $333^{\circ} \mathrm{C}$, com moda entre $218^{\circ}$ e $235^{\circ} \mathrm{C}$ (Tabela 1; Figura $4 d$ ).

As raras inclusões aquosas bifásicas mensuráveis encontradas em topázio do veio possuem Te entre $-28^{\circ}$ e $-26^{\circ} \mathrm{C}$ e provável fusão de hidrohalita entre $-17^{\circ} \mathrm{e}-14^{\circ} \mathrm{C}$. A fusão do gelo ocorre entre $-11^{\circ}$ e $-9^{\circ} \mathrm{C}$, o que permitiu estimar a salinidade entre 13 e $15 \%$ em peso de $\mathrm{NaCl}$ equiv. (Tabela 1; Figura 4c). A crepitação impediu a observação da homogeneização total.

No veio de quartzo + fluorita as inclusões fluidas são extremamente abundantes e ocorrem predominantemente ao longo de trilhas, sendo, portanto, interpretadas como secundárias (Figura $3 \mathrm{~g}$ ). As inclusões do tipo 2 do quartzo do veio têm forma alongada, por vezes retangular, e tamanho médio de $8 \mu \mathrm{m}$. A fusão do gelo ocorre entre $-14^{\circ} \mathrm{e}-3^{\circ} \mathrm{C}$, o que implica salinidade entre 4,9 e $17,8 \%$ em peso de $\mathrm{NaCl}$ equiv.. A homogeneização total ocorre entre $220^{\circ}$ e $333^{\circ} \mathrm{C}$, para a fase líquida (Tabela 1; Figura 4d).

As inclusões fluidas em topázio do greisen estudado são comumente alongadas e contêm cristais aprisionados, na sua maioria, birrefringentes (Figura $3 \mathrm{f}$ ). Os valores de temperatura do ponto eutético variam de $-35^{\circ} \mathrm{a}-25^{\circ} \mathrm{C}$ (Tabela 1 ), o que indica a provável presença de cátions divalentes dissolvidos na fase aquosa, possivelmente $\mathrm{Mg}^{2+}$ e $\mathrm{Fe}^{2+}$, além de $\mathrm{KCl}$ e $\mathrm{NaCl}$. A fusão do gelo ocorre entre $-9^{\circ} \mathrm{e}-6^{\circ} \mathrm{C}$, resultando em salinidade entre 9 e $13 \%$ em peso de $\mathrm{NaCl}$ equiv. (Tabela 1 ). A homogeneização total das inclusões aquosas faz-se em fase líquida entre $205^{\circ} \mathrm{e}$ $258^{\circ} \mathrm{C}$ (Tabela 1), com moda de $210^{\circ}$ a $230^{\circ} \mathrm{C}$ (Figura $4 \mathrm{~d}$ ).

Inclusões puramente aquosas em quartzo dos greisens são pouco freqüentes. Em geral, contêm sólidos birrefringentes, interpretados como capturados. Quando medida, a Tfg varia de $17^{\circ} \mathrm{a}-2^{\circ} \mathrm{C}$ (Tabela 1; Figura 4c), resultando em salinidade de 3,4 a 20,2 \% em peso de $\mathrm{NaCl}$ equiv.. A homogeneização total ocorre entre $216^{\circ}$ e $262^{\circ} \mathrm{C}$, para a fase líquida (Tabela 1; Figura 4d).

As inclusões fluidas primárias em fluorita do filão micáceo possuem dimensões inferiores a $10 \mu \mathrm{m}$ e se caracterizam por conter freqüentemente fases sólidas birrefringentes, interpretadas como minerais capturados. Inclusões líquidas monofásicas 

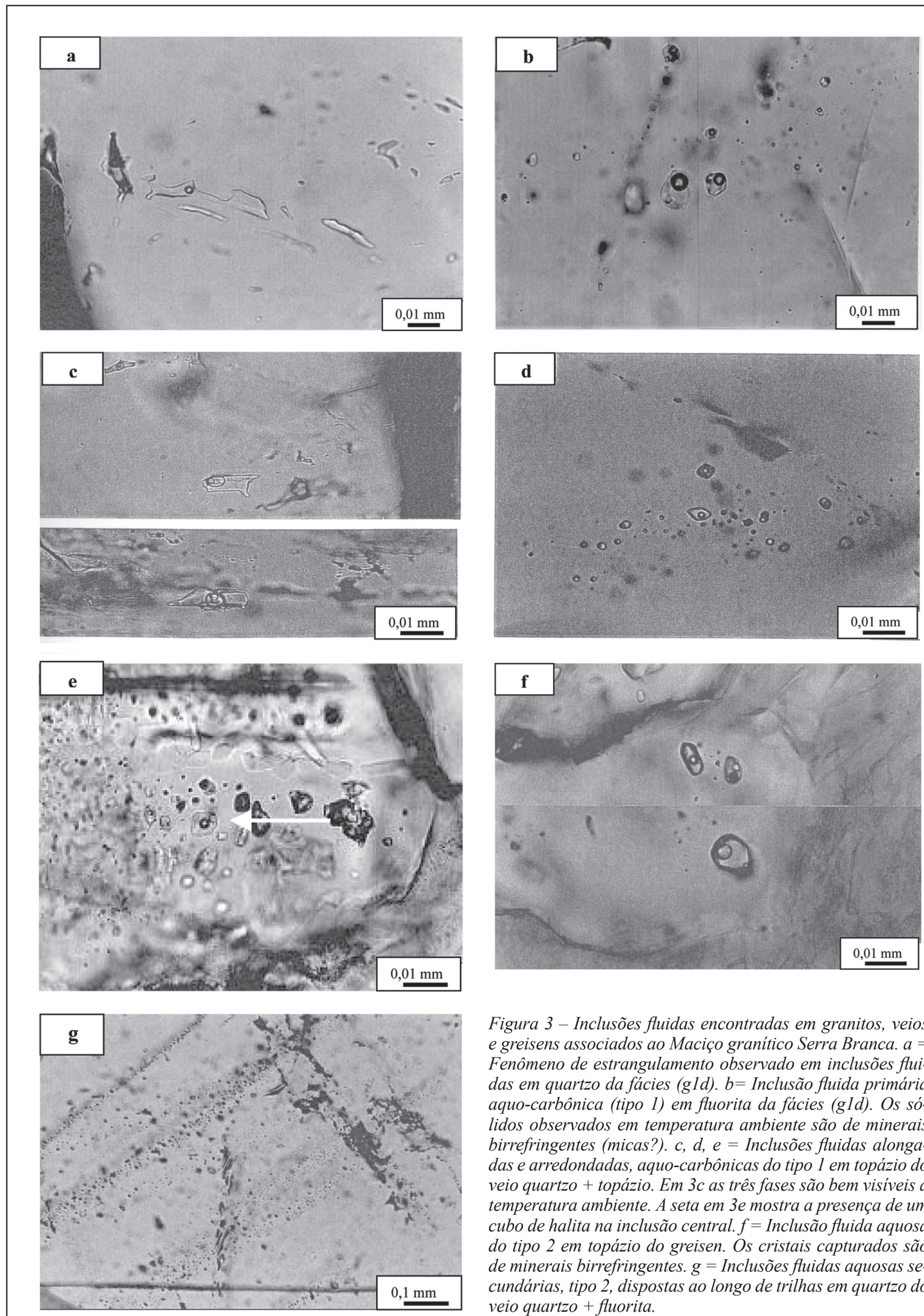

Figura 3 - Inclusões fluidas encontradas em granitos, veios e greisens associados ao Maciço granítico Serra Branca. $a=$ Fenômeno de estrangulamento observado em inclusões fluidas em quartzo da fácies ( $\mathrm{gld}$ ). b= Inclusão fluida primária aquo-carbônica (tipo 1) em fluorita da fácies (gld). Os sólidos observados em temperatura ambiente são de minerais birrefringentes (micas?). $c$, $d$, e = Inclusões fluidas alongadas e arredondadas, aquo-carbônicas do tipo 1 em topázio do veio quartzo + topázio. Em $3 c$ as três fases são bem visíveis à temperatura ambiente. A seta em 3 e mostra a presença de um cubo de halita na inclusão central. $f=$ Inclusão fluida aquosa do tipo 2 em topázio do greisen. Os cristais capturados são de minerais birrefringentes. $g=$ Inclusões fluidas aquosas secundárias, tipo 2, dispostas ao longo de trilhas em quartzo do veio quartzo + fluorita. 
Tabela 1 - Características petrográficas e microtermométricas das inclusões fluidas encontradas nas rochas do Maciço granítico Serra Branca.

\begin{tabular}{|c|c|c|c|}
\hline $\begin{array}{l}\text { TIPO DE INCLUSÃO } \\
\text { FLUIDA }\end{array}$ & $\begin{array}{c}\text { Rocha } \\
\text { Mineral hospedeiro } \\
\text { (número de medidas }=\text { n) }\end{array}$ & Características petrográficas & $\begin{array}{l}\text { Principais dados } \\
\text { microtermométricos }\end{array}$ \\
\hline \multirow[t]{7}{*}{$\begin{array}{l}\text { Tipo } 1(\mathrm{~L}+\mathrm{V}+\mathrm{V}) \\
\mathrm{H}_{2} \mathrm{O}-\mathrm{CO}_{2}-\mathrm{CH}_{4}-\mathrm{NaCl} \\
\left( \pm \mathrm{KCl}-\mathrm{FeCl}_{2}-\mathrm{MgCl}_{2}\right)\end{array}$} & $\begin{array}{l}\text { Fácies (gla) e }(\mathrm{glc}) \\
\text { Feldspato } \\
(\mathrm{n}=53)\end{array}$ & $\begin{array}{l}\text { Arredondadas a tabulares, paralelas a } \\
{[001] . \text { Fase sólida birrefringente comum. }} \\
5-10 \mu \mathrm{m} . \mathrm{F}=0,80\end{array}$ & $\begin{array}{l}\mathrm{TfCO}_{2}=-58,2^{\circ} \mathrm{a}-56,7^{\circ} \mathrm{C} \\
\left(\text { moda }=-57,5^{\circ} \mathrm{a}-57^{\circ} \mathrm{C}\right) ; \\
\mathrm{Tfg}=-0,9^{\circ} \mathrm{a}-0,1^{\circ} \mathrm{C} ; \mathrm{Th}(\mathrm{L})= \\
24^{\circ} \mathrm{a} 26^{\circ} \mathrm{C} ; \mathrm{TH}(\mathrm{L})=240^{\circ} \mathrm{a} \\
245^{\circ} \mathrm{C}\end{array}$ \\
\hline & $\begin{array}{l}\text { Fácies (g1d) } \\
\text { Quartzo } \\
(\mathrm{n}=9)\end{array}$ & $\begin{array}{l}\text { Comumente estiradas e estranguladas. } \\
\text { Raras. } 10-20 \mu \mathrm{m} . \mathrm{F}=0,90-0,95\end{array}$ & $\begin{array}{l}\mathrm{TfCO}_{2}=-56,9^{\circ} \text { a }-56,6^{\circ} \mathrm{C} \\
\mathrm{Tfg}=-10^{\circ} \mathrm{a}-4^{\circ} \mathrm{C} ; \mathrm{Th}(\mathrm{L}) \cong 28^{\circ} \mathrm{C} ; \\
\mathrm{TH}(\mathrm{L})=306^{\circ} \text { a } 335^{\circ} \mathrm{C}\end{array}$ \\
\hline & $\begin{array}{l}\text { Fácies (gld) } \\
\text { Fluorita } \\
(\mathrm{n}=22)\end{array}$ & $\begin{array}{l}\text { Arredondadas a tabulares. Fase sólida } \\
\text { birrefringente comum. Sólido isótropo } \\
\text { (halita?) presente. } 5-8 \mu \mathrm{m} \text {. } \\
\mathrm{F}=0,80-0,70\end{array}$ & $\begin{array}{l}\mathrm{TfCO}_{2}=-56,9^{\circ} \mathrm{a}-56,6^{\circ} \mathrm{C} ; \\
\mathrm{Tfg}=-2,2^{\circ} \mathrm{a}-0,5^{\circ} \mathrm{C} ; \mathrm{Th}(\mathrm{L})=26^{\circ} \mathrm{a} \\
29^{\circ} \mathrm{C} ; \mathrm{TH}(\mathrm{L})=245^{\circ} \text { a } 273^{\circ} \mathrm{C}\end{array}$ \\
\hline & $\begin{array}{l}\text { Veio de quartzo + topázio } \\
\text { Topázio } \\
(\mathrm{n}=78)\end{array}$ & $\begin{array}{l}\text { Alongadas, arredondadas, irregulares e } \\
\text { cristal negativo. Fase sólida birrefringente } \\
\text { comum. Sólido isótropo (halita?) } \\
\text { presente. } 5-12 \mu \mathrm{m} . \mathrm{F}=0,90-0,80\end{array}$ & $\begin{array}{l}\mathrm{TfCO}_{2}=-57,6^{\circ} \mathrm{a}-56,6^{\circ} \mathrm{C} ; \\
\mathrm{Te}=-33 \text { a }-24^{\circ} \mathrm{C} \mathrm{Tfg}=-12^{\circ} \mathrm{a}- \\
2^{\circ} \mathrm{C} ; \mathrm{Th}(\mathrm{L})=25^{\circ} \text { a } 30^{\circ} \mathrm{C} ; \mathrm{TH}(\mathrm{L}) \\
=190^{\circ} \text { a } 310^{\circ} \mathrm{C}\left(\operatorname{moda}=240^{\circ} \mathrm{a}\right. \\
\left.280^{\circ} \mathrm{C}\right)\end{array}$ \\
\hline & $\begin{array}{l}\text { Veio de quartzo + fluorita } \\
\text { Quartzo } \\
(\mathrm{n}=68)\end{array}$ & $\begin{array}{l}\text { Alongadas, irregulares e cristal negativo. } 5 \\
-20 \mu \mathrm{m} . \mathrm{F}=0,90-0,70\end{array}$ & $\begin{array}{l}\mathrm{TfCO}_{2}=-57,8^{\circ} \text { a }-56,6^{\circ} \mathrm{C} ; \\
\left(\text { moda }=-56,9^{\circ} \text { a }-56,6^{\circ} \mathrm{C}\right) ; \mathrm{Tfg}=- \\
6,9^{\circ} \mathrm{a}-3^{\circ} \mathrm{C} ; \mathrm{Th}(\mathrm{L})=27^{\circ} \text { a } 31^{\circ} \mathrm{C} ; \\
\mathrm{TH}(\mathrm{L})=250^{\circ} \text { a } 330^{\circ} \mathrm{C}(\operatorname{moda}= \\
\left.260^{\circ} \text { a } 280^{\circ} \mathrm{C}\right)\end{array}$ \\
\hline & $\begin{array}{l}\text { Greisen } \\
\text { Topázio } \\
(\mathrm{n}=5)\end{array}$ & $\begin{array}{l}\text { Alongadas, arredondadas. Raras. Fase } \\
\text { sólida birrefringente comum. } 5-15 \mu \mathrm{m} . \\
\mathrm{F}=0,90-0,80\end{array}$ & $\begin{array}{l}\mathrm{TfCO}_{2}=-57,1^{\circ} \mathrm{a}-56,6^{\circ} \mathrm{C} ; \\
\mathrm{Tfg}=-5,5^{\circ} \mathrm{a}-3^{\circ} \mathrm{C} ; \mathrm{TH}(\mathrm{L})=258^{\circ} \\
\text { a } 270^{\circ} \mathrm{C}\end{array}$ \\
\hline & $\begin{array}{l}\text { Greisen } \\
\text { Quartzo } \\
(n=42)\end{array}$ & $\begin{array}{l}\text { Alongadas, arredondadas. Comuns. Fase } \\
\text { sólida birrefringente comum. } 5-15 \mu \mathrm{m} \text {. } \\
\mathrm{F}=0,90-0,80\end{array}$ & $\begin{array}{l}\mathrm{TfCO}_{2}=-57,5^{\circ} \text { a }-56,6^{\circ} \mathrm{C} ; \\
\mathrm{Te}=-30 \text { a }-23^{\circ} \mathrm{C} ; \mathrm{Tfg}=-10^{\circ} \mathrm{a}- \\
2^{\circ} \mathrm{C} ; \mathrm{TH}(\mathrm{L})=255^{\circ} \text { a } 270^{\circ} \mathrm{C}\end{array}$ \\
\hline \multirow[t]{5}{*}{$\begin{array}{l}\text { Tipo } 2(\mathrm{~L}+\mathrm{V}) \\
\mathrm{H}_{2} \mathrm{O}-\mathrm{NaCl}\left( \pm \mathrm{KCl}-\mathrm{FeCl}_{2}\right. \\
\left.-\mathrm{MgCl}_{2}\right)\end{array}$} & $\begin{array}{l}\text { Fácies (g1d) } \\
\text { Quartzo } \\
(\mathrm{n}=26)\end{array}$ & $\begin{array}{l}\text { Alongadas. Estrangulamento freqüente. } \\
\text { Primárias e secundárias. } 10-20 \mu \mathrm{m} \text {. } \\
\mathrm{F}=0,90-0,95\end{array}$ & $\begin{array}{l}\mathrm{Tfg}=-17^{\circ} \mathrm{a}-2^{\circ} \mathrm{C} ; \\
\left(\operatorname{moda}=-9^{\circ} \mathrm{a}-6^{\circ} \mathrm{C}\right) ; \mathrm{TH}(\mathrm{L})= \\
216^{\circ} \text { a } 262^{\circ} \mathrm{C}\left(\operatorname{moda}=220^{\circ} \mathrm{a}\right. \\
\left.240^{\circ} \mathrm{C}\right)\end{array}$ \\
\hline & $\begin{array}{l}\text { Veio de quartzo + topázio } \\
\text { Topázio } \\
(n=2)\end{array}$ & $\begin{array}{l}\text { Alongadas, arredondas. } 5-15 \mu \mathrm{m} . \\
\mathrm{F}=0,90-0,95\end{array}$ & $\begin{array}{l}\mathrm{Te}=-28 \text { a }-26^{\circ} \mathrm{C} ; \text { Tfhidr }=-17^{\circ} \\
\mathrm{a}-14^{\circ} \mathrm{C} ; \mathrm{Tfg}=-11^{\circ} \mathrm{a}-9^{\circ} \mathrm{C}\end{array}$ \\
\hline & $\begin{array}{l}\text { Veio de quartzo + fluorita } \\
\text { Quartzo } \\
(\mathrm{n}=73)\end{array}$ & $\begin{array}{l}\text { Arredondas a retangulares. } 3-10 \mu \mathrm{m} \text {. } \\
\mathrm{F}=0,90-0,95\end{array}$ & $\begin{array}{l}\mathrm{Tfg}=-14^{\circ} \mathrm{a}-3^{\circ} \mathrm{C}\left(\text { moda }=-14^{\circ} \mathrm{a}-\right. \\
\left.12^{\circ} \mathrm{C}\right) ; \mathrm{TH}(\mathrm{L})=220^{\circ} \text { a } 333^{\circ} \mathrm{C}\end{array}$ \\
\hline & $\begin{array}{l}\text { Greisen } \\
\text { Topázio+fluorita } \\
(\mathrm{n}=25)\end{array}$ & $\begin{array}{l}\text { Alongadas. Sólido birrefringente comum. } \\
3-10 \mu \mathrm{m} . \mathrm{F}=0,90-0,80\end{array}$ & $\begin{array}{l}\mathrm{Te}=-35^{\circ} \text { a }-25^{\circ} \mathrm{C} ; \mathrm{TH}(\mathrm{L})=205^{\circ} \\
\text { a } 258^{\circ} \mathrm{C}\left(\operatorname{moda}=210^{\circ} \text { a } 230^{\circ} \mathrm{C}\right)\end{array}$ \\
\hline & $\begin{array}{l}\text { Greisen } \\
\text { Quartzo } \\
(\mathrm{n}=11)\end{array}$ & $\begin{array}{l}\text { Alongadas. Sólido birrefringente comum. } \\
5-15 \mu \mathrm{m} . \mathrm{F}=0,90-0,80\end{array}$ & $\begin{array}{l}\mathrm{Tfg}=-17^{\circ} \mathrm{a}-3^{\circ} \mathrm{C} ; \mathrm{TH}(\mathrm{L})=216^{\circ} \\
\text { a } 262^{\circ} \mathrm{C}\end{array}$ \\
\hline
\end{tabular}

dispostas ao longo de trilhas, secundárias, diminutas e arredondadas também estão presentes. A fusão do gelo, dificilmente observável, situa-se entre $-2,4^{\circ} \mathrm{e}-0,8^{\circ} \mathrm{C}$, com salinidades calculadas entre 1,4 e $4 \%$ em peso de $\mathrm{NaCl}$ equiv. (Tabela 1 ). A temperatura de homogeneização total situa-se entre $180^{\circ}$ e $268^{\circ} \mathrm{C}$, com freqüente crepitação. Fenômenos de estrangulamento são comumente observados.

Interpretação dos dados de inclusões fluidas As inclusões fluidas aquo-carbônicas (tipo 1) representam provavelmente o fluido mais precoce do sistema magmático-hidrotermal do maciço, aprisionado tanto nos granitos, como nas diferentes rochas hidrotermais estudadas. Possuem características e composições semelhantes em todos os tipos de rocha em que ocorrem e caracterizam-se por salinidade baixa a média, presença de $\mathrm{CH}_{4}$ adicionado ao $\mathrm{CO}_{2}$, densidade média a alta e temperatura de homogeneização total $\left(\mathrm{T}_{\mathrm{H}}\right)$ entre $190^{\circ}$ e $335^{\circ} \mathrm{C}$ (Tabela 1). Os valores mais elevados de $\mathrm{T}_{\mathrm{H}}$ foram obtidos em quartzo da fácies 

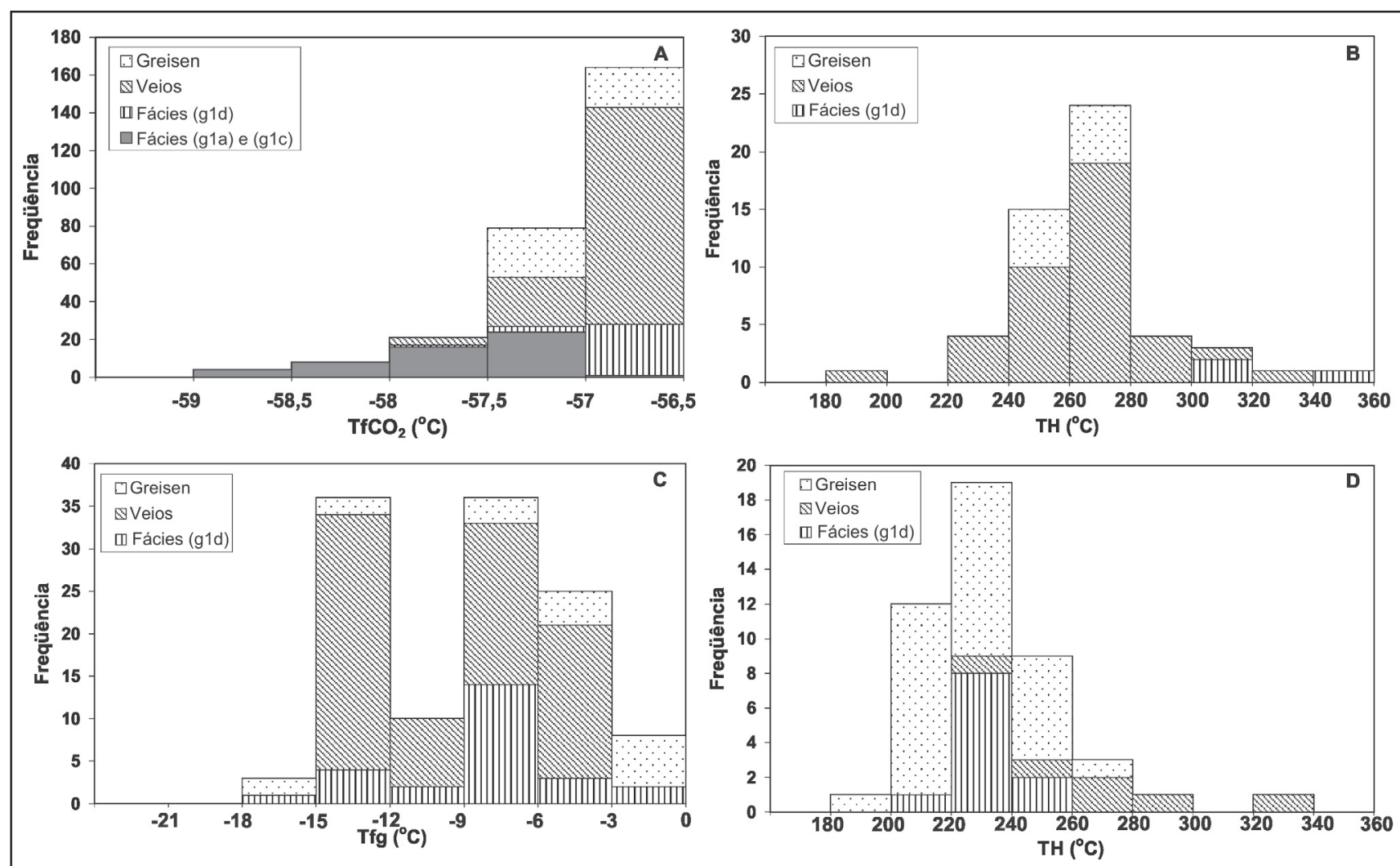

Figura 4 - Dados microtermométricos das inclusões fluidas aquo-carbônicas do tipo 1 (4a e 4b) e inclusões aquosas do tipo 2 (4c e 4d) em rochas do Maciço granítico Serra Branca.

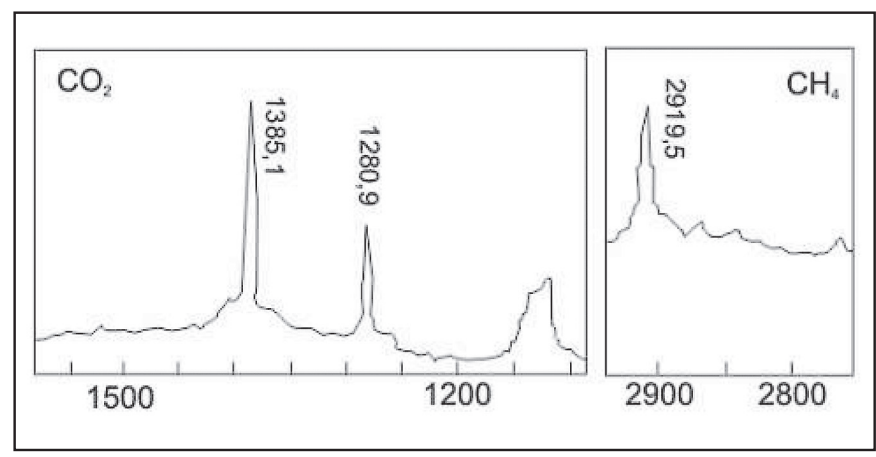

Figura 5 - Espectroscopia Raman de inclusões fluidas aquocarbônicas do tipo 1 em feldspato alcalino precoce da fácies (glc) mostrando a presença de $\mathrm{CO}_{2} e \mathrm{CH}_{4}$

(g1d) e os mais baixos, em topázio de veio e em feldspato das fácies (g1a) e (g1c). Os baixos valores de $T_{H}$ e de salinidade das inclusões fluidas dos núcleos dos feldspatos alcalinos sugerem que essas porções não contêm mais o fluido magmático aprisionado, mas fluidos resultantes de resfriamento progressivo ou de alteração hidrotermal.

Os fluidos do sistema $\mathrm{H}_{2} \mathrm{O}-\mathrm{NaCl}\left( \pm \mathrm{KCl}-\mathrm{MgCl}_{2}-\mathrm{FeCl}_{2}\right.$ ) possuem temperatura mínima de aprisionamento no intervalo de $180^{\circ}$ a $330^{\circ} \mathrm{C}$ e características petrográficas de inclusões fluidas primárias nas rochas hidrotermais e de inclusões fluidas secundárias nas amostras da fácies (g1a) e de veios de quartzo + fluorita. As inclusões fluidas primárias em fluorita e topázio representam, provavelmente, fluido hidrotermal resultante da evolução do fluido magmático ou de possível mistura de fluidos magmáticos com água externa, provavelmente meteórica.
As inclusões fluidas secundárias de quartzo do granito e de veio de quartzo+fluorita e primárias de quartzo dos greisens contêm provavelmente fluido tardio relacionado ao evento Brasiliano, sem relação com a mineralização de estanho.

Devido à ausência de evidências de aprisionamento simultâneo de dois fluidos imiscíveis, levando-se em consideração as observações de Roedder \& Bodnar (1980) para inclusões fluidas consideradas contemporâneas, não foram utilizados diagramas de isócoras para a determinação de valores de pressão e temperatura de aprisionamento dos fluidos. Entretanto, em analogia com depósitos semelhantes, o depósito da Serra Branca é interpretado como sendo relativamente raso, formado em profundidade de $\sim 1-3 \mathrm{~km}$. Os valores de temperatura de homogeneização total das inclusões fluidas aquo-carbônicas de cristais de quartzo da fácies (g1d) $\left(306^{\circ}\right.$ a $\left.335^{\circ} \mathrm{C}\right)$ são interpretados como valores mínimos de aprisionamento do fluido primário do sistema magmático-hidrotermal do maciço. Nos greisens e veios, as temperaturas mínimas de aprisionamento situam-se predominantemente entre $250^{\circ}$ e $280^{\circ} \mathrm{C}$, valores que podem ser decorrentes de resfriamento do fluido durante a evolução do fluido hidrotermal e mineralização.

As inclusões fluidas presentes em grande abundância nos feldspatos alcalinos dos granitos do MGSB têm características de inclusões primárias: orientação cristalográfica, contemporaneidade com o crescimento da porção central dos feldspatos, anterioridade aparente com relação aos fenômenos subsolidus de exsolução e de inversão de simetria, ou pelo menos do aumento do grau de ordenamento (crescimento das maclas de inversão em direção ao ordenamento máximo do microclínio). Tais inclusões aparentam contemporaneidade com a primeira geração de feldspato alcalino cristalizado sob forma de fenocristais; a segunda geração, nas bordas ou em placas isoladas na matriz, é sistematicamente desprovida de inclusões. Sua distribuição e 
morfologia regular são opostas àquelas responsáveis pelo aspecto turvo apresentado por feldspatos (Folk 1955) e que resultam de dissolução hidrotermal (Worden et al. 1990). Entretanto, os baixos valores de $\mathrm{T}_{\mathrm{H}}$ obtidos sugerem que, embora relativamente precoces, os fluidos aprisionados nos núcleos do feldspato potássico provavelmente não representam o fluido magmático, mas provavelmente se associam a hidrotermalismo.

DISCUSSÃO E CONCLUSÕES Os dados de inclusões fluidas apresentados demonstram que a deformação relacionada à orogênese Brasiliana está extensamente registrada nos granitos e nas rochas hidrotermais do maciço granítico Serra Branca (MGSB). Dados geocronológicos K/Ar confirmam, igualmente, a superimposição desse evento térmico-deformacional (PintoCoelho 1996). Entretanto, fluidos primários encontram-se preservados em quartzo, topázio e em fluorita. Nos cristais de quartzo, devido à deformação e forte recristalização, inclusões fluidas precoces são mais raras. Portanto, o quartzo é o mineral que melhor testemunha a recristalização contemporânea e posterior à deformação que afetou as rochas do MGSB. As inclusões fluidas estudadas no quartzo correspondem, predominantemente, à cicatrização de fenômenos tectônicos e evidenciam a circulação de fluidos durante e após a deformação. Quando presentes, as inclusões fluidas mais precoces são predominantemente aquocarbônicas, modeladas pelo sistema $\mathrm{H}_{2} \mathrm{O}-\mathrm{NaCl}-\mathrm{CO}_{2}\left( \pm \mathrm{CH}_{4}\right)$ e aprisionadas em quartzo e fluorita de granito e em quartzo, topázio e fluorita nas zonas de alteração hidrotermal mineralizadas. Os fluidos aquosos, modelados pelo sistema $\mathrm{H}_{2} \mathrm{O}-\mathrm{NaCl}$ $\left( \pm \mathrm{KCl}-\mathrm{MgCl}_{2}-\mathrm{FeCl}_{2}\right)$, parecem ser posteriores aos fluidos ricos em $\mathrm{CO}_{2}$ aprisionados nos granitos. Estão relacionados tanto a evento hidrotermal, em que inclusões fluidas aquosas primárias coexistem com inclusões aquo-carbônicas nos minerais dos greisens e veios, quanto a evento tardio, provavelmente sem relação com a mineralização.

Inclusões fluidas aquo-carbônicas primárias em associação com inclusões aquosas são descritas em sistemas hidrotermais associados a mineralizações de estanho e tungstênio (Frantz et al. 1998, Linnen 1998, Rios et al. 2003). No Brasil, em outros depósitos de estanho relacionados a granitos intraplaca, os sistemas de fluidos descritos são muito semelhantes aos observados na Serra Branca. Na Província Estanífera de Goiás, inclusões fluidas $\mathrm{H}_{2} \mathrm{O}-$ $\mathrm{CO}_{2}-(\mathrm{NaCl})\left(0-4 \%\right.$ em peso de $\mathrm{NaCl}$ equiv.; $\left.\mathrm{T}_{\mathrm{H}}=250-400^{\circ} \mathrm{C}\right)$ estão preservadas em quartzo de granito e em quartzo e topázio de rocha hidrotermal mineralizada; inclusões $\mathrm{H}_{2} \mathrm{O}-\mathrm{NaCl}$, com $\mathrm{T}_{\mathrm{H}}=$ $300-450^{\circ} \mathrm{C}$, tanto saturadas como bifásicas, ocorrem em granito e em veio de topazito mineralizado (Moura et al. 2004). Em granitos mais jovens em Rondônia, inclusões fluidas primárias aquocarbônicas $\left(\mathrm{T}_{\mathrm{H}}=245-450^{\circ} \mathrm{C}\right)$ e inclusões fluidas bifásicas aquosas $\left(T_{H}=100-380^{\circ} \mathrm{C}\right)$ foram descritas em granito e em greisen mineralizado dos depósitos de Santa Bárbara, Correas e Oriente Novo (Bettencourt et al. 2005). No depósito de estanho do Bom Futuro, com base em estudo de inclusões fluidas em cassiterita, Souza \& Botelho (2003) propuseram que os fluidos responsáveis pela mineralização pertencem ao sistema $\mathrm{H}_{2} \mathrm{O}-\mathrm{NaCl}-\mathrm{CO}_{2}$ $\left( \pm \mathrm{CH}_{4} \pm \mathrm{N}_{2}\right)$ e que a precipitação de cassiterita ocorreu pelo menos entre 360 e $400^{\circ} \mathrm{C}$ e $1-2 \mathrm{~km}$ de profundidade.

Embora sejam descritos fluidos contendo $\mathrm{CO}_{2}$ em depósitos minerais de associação granítica, a origem desses fluidos, se metamórfica ou magmática, é controversa (p.ex. Linnen 1998, Baker \& Lang 2001, Rios et al. 2003). Entretanto, alguns estudos confirmam a presença de dióxido de carbono dissolvido em magmas félsicos, que particiona fortemente para a fase volátil (Burnham \& Ohmoto 1980, Lowenstern 2001). Os dados experimentais apontam para aumento de solubilidade de $\mathrm{CO}_{2}$ com o aumento da pressão e a alcalinidadade do magma (Lowenstern 2001). Os fluidos carbônicos são pouco miscíveis com fluidos aquosos, particularmente a temperaturas elevadas e baixa pressão, de modo que a presença de $\mathrm{CO}_{2}$ pode induzir imiscibilidade, tanto em sistemas magmáticos como hidrotermais, e contribuir indiretamente com o processo de mineralização, por induzir a separação de fases (Lowenstern 2001).

Segundo Burnham \& Ohmoto (1980), magmas que geram mineralização de estanho caracterizam-se por possuírem fugacidade de oxigênio geralmente abaixo do tampão QFM e razões $\mathrm{CO}_{2} / \mathrm{CH}_{4}$ de fugacidade e fração molar aproximadamente unitárias. Conseqüentemente, as abundâncias relativas de espécies reduzidas e oxidadas nos fluidos aquosos que se separam desses magmas são geralmente: $\mathrm{mCO}_{2} \cong \mathrm{mCH}_{4} \cong \mathrm{mH}_{2} \mathrm{~S} \gg \mathrm{SO}_{2}$, o que torna comum a precipitação de pequenas quantidades de sulfetos e grandes quantidades de óxidos durante o resfriamento. Isso possibilita a ocorrência de mineralização rica em $\mathrm{Sn}$ e pobre em enxofre, devido à menor quantidade de enxofre total nos líquidos. Ainda, a precipitação de metais produz $\mathrm{HCl}$, que é responsável por alteração ácida de baixa temperatura.

Os fluidos magmáticos são considerados como estando em equilíbrio com a assembléia granítica quartzo-feldspato-(mica). Assim, serão as variações nos parâmetros intensivos que irão modificar seu comportamento, ou seja, a evolução do fluido depende de variações de $\mathrm{T}$ e $\mathrm{P}$ do sistema e não da composição do mesmo em função de reação com o hospedeiro ou, ainda, da mistura com outros fluidos. Queda de pressão torna esses fluidos menos ácidos, favorecendo a precipitação do feldspato e a lixiviação da sílica, e a queda de temperatura terá efeito inverso: os fluidos tornam-se excessivamente ácidos (tampão quartzofeldspato-mica), desenvolvendo greisens (Charoy 1979, Fonteilles \& Pascal 1985, Wright \& Kwak, 1988), que hospedam mineralização de estanho no MGSB. Os fluidos responsáveis pela formação dos filões micáceos associados às fácies graníticas do MGSB precipitaram predominantemente fengita, o que testemunha uma acidez mínima favorecendo a mobilização do Al. A deposição do microclínio (fase de microclinização), por outro lado, indicaria um aumento da alcalinidade dos fluidos.

As características petrológicas das fácies graníticas do maciço Serra Branca, juntamente com os dados de inclusões fluidas, apesar de não permitirem descartar fonte externa para os fluidos aquo-carbônicos, são consistentes com fonte predominantemente magmática para os fluidos ricos em $\mathrm{CO}_{2}\left( \pm \mathrm{CH}_{4}\right)$. Os dados microtermométricos sugerem que os fluidos aquosos são posteriores aos fluidos aquo-carbônicos. A evolução desses fluidos deve ter resultado de liberação seqüencial de um fluido magmático, boiling durante o resfriamento ou mistura de fluidos. Evidências de que tenha ocorrido boiling estão ausentes nas amostras estudadas.

Os resultados obtidos no MGSB e os dados acerca do comportamento do $\mathrm{CO}_{2}$ durante a evolução magmático-hidrotermal de fluidos exsolvidos de magmas félsicos favorecem um modelo misto em que tenha ocorrido liberação residual de um fluido inicialmente magmático e mistura com fluido externo de mais baixa temperatura. A precipitação de metais poderia decorrer da evolução progressiva dos fluidos, devido a mudanças nas condições de pressão e/ou temperatura, ou da mistura de fluidos magmáticos com fluidos externos. Após a alteração hidrotermal e mineralização, houve aprisionamento de fluidos tardios em fraturas de minerais hidrotermais, provavelmente resultantes de aporte de fluidos externos de baixa temperatura. Os dados, portanto, mostram que a história evolutiva dos fluidos no depósito da Serra Branca é complexa e, pelo menos, uma fase desta evolução deve estar ligada ao Ciclo Brasiliano e não apenas às alterações pós-magmáticas.

Agradecimentos Aos revisores anônimos da Revista Brasileira de Geociências pelas críticas e sugestões apresentadas. 


\section{Referências}

Andrade G.F. de 1978. As mineralizações de estanho, berilio e cobre do granito da Serra Branca, Cavalcante - Goiás. Dissertação de Mestrado,Universidade de Brasília, 83 p.

Baker T. \& Lang J. 2001. Fluid inclusion characteristics of intrusionrelated gold mineralization, Tombstone-Tungsten magmatic belt, Yukon Territory, Canada. Miner. Dep., 36:536-582.

Bettencourt J.S., Leite J.W.B., Goraieb C. L., Sparrenberger I., Mello R.M.S., Payola B. 2005. Sn polymetallic greisen-type deposits associated with late-stage rapakivi granites, Brazil: fluid inclusion and stable isotope characteristics. Lithos, 80:363-386.

Botelho N.F. 1992. Les ensembles granitiques subalcalins a peralumineux minéralisés en Sn et In de la sous-province Paranã, Etat de Goiás, Brésil. Tese de Doutoramento, Paris VI, 344 p.

Botelho N.F. \& Moura M.A. 1998. Granite-ore deposit relationship in central Brazil. Journal of South America Earth Sciences, 11:427438.

Burnham C. \& Ohmoto H. 1980. Late-stage processes of felsic magmatism: Mining Geology, 8:1-11.

Charoy B. 1979. Définition et importance des phénomènes deutériques et des fluides associés dans les granites. Conséquences métallogéniques. Tese de Doutoramento, INPL, $277 \mathrm{p}$.

Folk R. L. 1955. Note on the significance of "turbid" feldspars. Amer. Mineral., 40:356-357.

Fonteilles M. \& Pascal M.L. 1985. Greisens, veines à quartz muscovite et zones feldspathisées comme éléments d'une même colonne métassomatique.C.R.Acad. Sci. (Paris), Sér. II, 300:755-758.

Frantz J.C., Coelho C.E., Botelho N.F. 1998. Gênese e evolução dos fluidos envolvidos na alteração hidrotermal e na mineralização de estanho em granitos do Rio Grande do Sul. Rev. Bras. Geoc., 28:301306.

Goldstein R.H. \& Reynolds T.J. 1994. Systematics of fluid inclusion in diagenetic minerals. SEPM Short Course 31. SEPM, Oklahoma, $198 \mathrm{p}$.

Le Maître R.W., Batemman P., Dudek A., Keller J., Lameyre J., Le Bas M.J., Sabine P.A., Schmidt R., Sorensen H., Streckeisen A., Wooley R.A., Zannettin B. 1989. A classification of igneous rocks and glossary of terms. Recommendation of the International Union of Geological Sciences. Subcommission on the Systematics of Igneous Rocks. Blackwell Scientific Publications, Oxford, UK,

Lenharo S.L.R., Moura M.A., Botelho N.F. 2002. Petrogenetic and mineralization processes in Paleo - to Mesoproterozoic rapakivi granites: example from Pitinga and Goiás, Brazil. Precambrian Research, 119:277-299.
Linnen R.L. 1998. Depth of emplacement, fluid provenance and metallogeny in granitic terranes: a comparison of western Thailand with other tin belts. Miner. Deposita, 33:461-476.

Lowenstern J.B. 2001. Carbon dioxide in magmas and implications for hydrothermal systems. Miner. Deposita, 36:490-502.

Marini O.J. \& Botelho N.F. 1986. A Província Estanífera de Goiás. Rev. Bras. Geoc., 22:8-19.

Moura M.A., Botelho N.F., Olivo G.R., Kyser T.K., Pontes R.M. 2004. Fluid geochemistry and evolution of the Mangabeira topaz-albite granite and related tin-indium mineralization (Goiás, Brasil). In: SBG, Congresso Brasileiro de Geologia, 42, Anais. (CD-Rom).

Pinto-Coelho C. 1996. Evolution magmatique et hydrothermale du Massif granitique de Serra Branca - Etat de Goiás - Brésil: définition des processus d'altération post-magmatique en liaison avec les minéralisations en $\mathrm{Sn}$, Be et $F$. Tese de Doutoramento, INPL,.271 p.

Pinto-Coelho C. \& Charoy B. 2001. Cronologia das alterações pósmagmáticas associadas ao Maciço Granítico da Serra Branca - Goiás. Rev. Bras. Geoc., 31:1-6.

Pinto-Coelho C., Botelho N.F., Roger G. 1999. Mobilité des terres rares au cours des altérations hydrothermales: l'exemple du granite de Serra Branca- Brésil Central. C.R. Acad. Sci. Paris, 328:663-670.

Rios F.J., Villas R.N., Fuzikawa K. 2003. Fluid evolution in the Pedra Preta wolframite ore deposit, Paleoproterozoic Musa granite, eastern Amazon craton, Brazil. J. South Am. Earth Sci., 15:787-802.

Roedder E. \& Bodnar R.J. 1980. Geologic pressure determinations from fluid inclusion studies. Annual Review of Earth and Planetary Sciences, 8:263-301.

Shepherd T.J., Rankin A. H., Alderton D.H.M. 1985. A practical guide to fluid inclusion studies. Chapman and Hall, New York, 239 p.

Souza V. da S. \& Botelho N.F. 2003. Geologia do depósito de estanho do Bom Futuro (Rondônia) e composição dos fluidos nos sistemas de veios e greisens. In: SBG, Contribuição à Geologia da Amazônia, v. 3, p. 199-214.

Worden R.H., Walker F.D.L., Parsons I., Brown, W.L. 1990. Development of microporosity, diffusion channels and deuteric coarsening in perthitic alkali feldspars. Contr. Mineral. Petrol., 104:507-515.

Wright J.H. \& Kwak T.A.P. 1988. Endogreisen, brecciation and fluid activity at the Mount Bischoff Sn-deposit, North-west Tasmânia, Austrália. Journ. Metamorph. Geol., 6:629-650.

Manuscrito AE008 Aprovado em 23 de julho de 2006 